\title{
Medicina e pensamento social brasileiro: personagens, linhagens e possibilidades históricas
}

\author{
Medicine and Brazilian social thought: \\ characters, lines and historical possibilities
}

\author{
Simone Meucci \\ Professora, Departamento de Ciência Política e Sociologia/Universidade Federal do Paraná. \\ simonemeucci2010@gmail.com
}

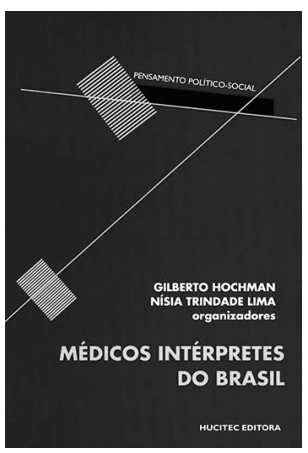

HOCHMAN, Gilberto; LIMA, Nísia Trindade (Org.). Médicos intérpretes do Brasil. São Paulo: Hucitec. 2015. 666p.
Gse livro tem como objetivo apresentar um conjunto de médicos Eque colaboraram para a urdidura de percepções acerca da sociedade, do povo e da nação brasileira. Não é propriamente uma novidade o reconhecimento de que médicos foram - assim como engenheiros e juristas - importantes intérpretes do Brasil. No entanto, nesse livro, em especial, são reunidos muitos personagens com diferentes perspectivas, o que favorece uma visão mais nítida e sofisticada do fenômeno. Sua leitura mostra tantos destinos paralelos e cruzados e tantos embates e diálogos, que é capaz de produzir algo parecido ao efeito do enredo sintetizado por Wolf Lepenies (1996), em As três culturas, sobre a constituição da ciência social na Europa: uma perspectiva muito viva e pulsante das ideias e dos intelectuais em sua relação com o ambiente social. É possível sentir, nas páginas de Médicos intérpretes do Brasil, os embaraços, lutas, esperanças, fracassos e vaidades dos médicos que elaboraram, na forma de tratados científicos, discursos de formatura ou textos literários, bem como suas interpretações do Brasil.

Nos capítulos, figuram, ao todo, 29 médicos intérpretes já falecidos, cronologicamente ordenados segundo o ano de seu nascimento. Foram selecionados não apenas pela repercussão, mas também, em alguns casos, pelo significado emblemático de suas ideias e ações na sociedade. Entre os mais conhecidos estão, por exemplo, Josué de Castro, Carlos Chagas e Nise da Silveira. Há também os menos conhecidos como Mendes Fradique, Porto-Carrero, Gentile de Mello e Francisca Praguer Fróes. A seleção incluiu ainda alguns autores que dificilmente lembramos como médicos, ainda que sejam notáveis como intérpretes do Brasil, a exemplo de Juscelino Kubitschek e Graciliano Ramos.

Essa escolha nos possibilita acompanhar ações e ideias ocorridas num intervalo de tempo que vai da segunda metade do século XIX até a primeira década do século XXI, permitindo-nos 
percorrer trajetórias de Nina Rodrigues a Zilda Arns e a história nacional desde o Segundo Império até os renitentes desafios pós-democratização.

Há, no entanto, uma notável concentração de intérpretes selecionados (21) que nasceram no intervalo entre 1862 e 1905 e cuja contribuição principal ocorreu no período que vai da década de 1880 à de 1930, quando se realizava o balanço de possibilidades e limites dos ideais republicanos em sua alvorada e em seu primeiro ocaso. Nessa época, as condições da divisão intelectual do trabalho, somadas aos desafios para a organização do Estado e a formulação de uma identidade nacional, pareciam convidar egressos das faculdades de medicina (da Bahia e do Rio de Janeiro em particular) para as tarefas de interpretar a vida social. Os médicos, como intelectuais polivalentes, representantes emblemáticos do pensamento científico, estavam então envolvidos no debate social, constituindo simultaneamente a ciência médica e a ciência social.

A organização do livro é singular. Cada capítulo dedica-se a um dos médicos intérpretes e é dividido em duas partes: a primeira, uma introdução com dados gerais sobre sua trajetória, elaborada por pesquisadores que formulam algumas vias de acesso às suas obras, além de hipóteses sugestivas; a segunda, um texto do médico em questão, representativo da perspectiva que se pretende destacar.

Nesse sentido, o livro reúne ainda alguns dos melhores pesquisadores da história das ciências médicas e sociais no Brasil, especialmente cientistas sociais e historiadores, mas também médicos, nutricionistas, físicos e psicólogos que atuam como "intérpretes dos intérpretes". Destaquemos, aliás, dentre os autores que interpretam a vida e a obra dos médicos, o também médico Moacyr Scliar que preparou um texto sobre Noel Nutels, concluído cerca de um mês antes de sua morte. Por certo, Scliar poderia agora também figurar entre os importantes médicos intérpretes do Brasil que o livro apresenta.

Com efeito, são páginas com muitas vozes que nos arremessam para tempos, olhares e lugares distintos (Rondônia, Pernambuco, São Paulo ou Santa Catarina). Não obstante, não se trata de uma coletânea, um daqueles livros fragmentados, tão comuns hoje. Esse livro é um mosaico (o termo é dos próprios organizadores) bem composto, cujas partes foram reunidas de modo a favorecer um quadro geral sobre a constituição do pensamento social no Brasil: agentes, instituições, referências teóricas e seus modos de apropriação, além dos dilemas fundamentais.

É um trabalho resultante de atividades interinstitucionais de pesquisa e divulgação nas áreas de pensamento social e saúde, algumas capitaneadas pelo grupo de pesquisa "Ciência, pensamento social e saúde" do Programa de Pós-graduação em História das Ciências e da Saúde da Casa de Oswaldo Cruz/Fiocruz. Nesse sentido, são páginas produzidas por uma reflexão coletiva que orienta algumas hipóteses sobre os nexos entre saúde, ciências sociais, educação, política e literatura.

A primeira questão que me parece importante destacar das páginas desse livro é que a representação da doença presente nos escritos dos médicos intérpretes não é apenas uma condição individual que pode ser combatida pela ação terapêutica, mas um "enigma revelador" das articulações entre indivíduo e sociedade. As doenças parecem ser expressão do estado geral da nação e do povo, evidência da necessidade imperiosa de profilaxia social. Nesse sentido, 
as doenças aparecem, igualmente, como objeto de análise, categoria heurística e fundamento de ação política; ou seja, a um só tempo, indagam, explicam e mobilizam soluções para a sociedade.

$\mathrm{Na}$ literatura, em particular, os médicos representam a doença como experiência que conduz ao esclarecimento. Isso é especialmente destacado na imaginação febril dos personagens de Guimarães Rosa que são vítimas de malária, mas é também observado na galhofa de Mendes Fradique que analisa certos hábitos da vida cultural brasileira como se fossem também doentios.

De fato, o Brasil era, com muita frequência, representado como um paciente ou como um imenso hospital ou hospício; sempre necessitado da ação intelectual e prática dos portadores do conhecimento médico-social.

Não se pode ainda ignorar que a prática médica é também submetida à análise dos intérpretes, como se observa, por exemplo, no memorialismo imaginativo de Pedro Nava, que narra os médicos de subúrbio, refletindo sobre suas atividades clínicas e seus alcances. Nesse sentido, também é alvo de reflexão, além da doença, a própria atividade médica, cujas condições são também uma das vias de acesso à vida social.

Com efeito, a maioria dos médicos intérpretes, em seus esforços para desvendar os fundamentos dos comportamentos criminosos, alucinações, infecções e afecções, reflete sobre fatores determinantes que, em geral, condicionavam não apenas o destino das vítimas particulares, mas o de toda a coletividade. Os intérpretes construíram, assim, a representação da doença, da medicina e da sociedade, além de contribuir para as formulações intelectuais e possibilidades históricas.

As doenças a interpretar e combater ultrapassavam o corpo e tomavam a forma de patologias abrangentes, menos referidas aos indivíduos do que ao ambiente. É assim que as epidemias e endemias urbanas e rurais são interpretadas como resultantes da precariedade das condições sanitárias ou nutricionais; que as doenças mentais dos negros e mestiços são compreendidas como produto de determinações raciais ou de relações sociais degradantes e os problemas da saúde da mulher (físicos e psíquicos) são relacionados à desigualdade de gênero e hábitos sexuais nocivos dos homens.

Com efeito, como segundo ponto a ser destacado, vale lembrar que o escrutínio das origens das doenças, em suas múltiplas abordagens teóricas, explicita um painel de tradições interpretativas que contribuiu, também, para o desenvolvimento do pensamento sociológico em seu embate com os determinismos raciais e geográficos. Os médicos intérpretes se dedicavam a identificar e comprovar se era a fome, o trópico, a precariedade sanitária, as disposições psíquico-culturais, o legado da escravidão ou do sangue que concorriam, afinal, para as patologias dos indivíduos e da nação.

Conforme as páginas do livro, as tarefas de interpretação exigiram a mobilização de uma fortuna intelectual que vai de Lombroso a Freud, de Galton a Manson, passando por Humboldt e La Blache, para citar apenas alguns. Um rico repertório de autores, sobretudo europeus, foi mobilizado para fundamentar ideias e debates que contribuíram para opor deterministas raciais, geográficos e sociais, e também para embaralhá-los e combiná-los em argumentos complexos ou tortuosos, reveladores da difícil artesania das ideias e das áreas de conhecimento. 
De fato, o livro nos mostra como a apropriação de ideias para o exame de novos fenômenos exige um trabalho de ressignificação. No caso dos médicos intérpretes, esse trabalho é notável; observado, por exemplo, na preocupação de Carlos Chagas em redefinir e justificar a prática da medicina tropical que na Europa esteve relacionada à ideologia colonial e no Brasil teria por função inspirar o projeto de construção nacional; ou na leitura de Freud feita por PortoCarrero, que aplicou de modo singular os conceitos da psicanálise à interpretação do Brasil, um país que, segundo sua perspectiva, era incapaz de superar a soberania do pai totêmico, incapaz também de levar a efeito seus movimentos sociais e políticos, resultando numa nação com tantos recalques quantas raças.

No entanto, especialmente os embates entre higienistas, sanitaristas e eugenistas carregam alguns dos dilemas fundantes da identidade nacional, afetada ora pela composição racial da população ou pela inoperância das instituições, ora pela fome ou pelos efeitos do clima tropical. Dessas perspectivas e da engenharia dos argumentos é que se justificavam terapêuticas que variavam entre a vacina, a profilaxia matrimonial, o branqueamento da população, a urbanização ou a nutrição.

Por fim, creio ser importante destacar que, frequentemente, devido o diagnóstico tão abrangente, a terapia recomendada remetia a ações que ultrapassavam a competência médica, situando os médicos em novas esferas de atividade que incluem os movimentos sociais católicos, movimentos nacionalistas, o campo educacional ou as reformas políticoadministrativas no interior do Estado - além de universidades, associações científicas e institutos de pesquisa.

Especialmente nas décadas de 1920 e 1930, a aproximação dos médicos com os pioneiros da educação foi frequente no Brasil. Apostavam na alfabetização, na inovação da prática pedagógica e na racionalização do conteúdo escolar para o paulatino melhoramento, por esclarecimento, das condições de saúde da população.

As páginas do livro demonstram, portanto, as diversas formas de atuação e a capilaridade dos médicos na sociedade. Mas revelam também as ideias que, a despeito da capacidade de mobilização, não repercutiram em suas consequências efetivas. Nesse sentido, o livro expressa as possibilidades históricas para construção da nação brasileira, mostrando os projetos em elaboração, seus limites e alcances. E provoca a vontade, em pesquisadores iniciantes e veteranos, de explorar ainda mais a trajetória dos médicos intérpretes - até sugerindo a análise de novos médicos, originários de outras regiões e linhagens teóricas, que também compuseram essa tessitura do pensamento e das alternativas históricas.

\section{REFERÊNCIA}

LEPENIES, Wolf.

As três culturas. Trad. Maria Clara Cescato.

São Paulo: Edusp. 1996. 